\title{
Synthesis and single crystal growth of gallium phosphide by the liquid encapsulated vertical Bridgman technique
}

\author{
K GOVINDA RAJAN, N V CHANDRA SHEKAR, G V N RAO, \\ A J SINGH* and R M IYER* \\ Materials Science Division, Indira Gandhi Centre for Atomic Research, Kalpakkam \\ 603102 , India \\ *Chemistry Division, Bhabha Atomic Research Centre, Bombay 400 085, India \\ MS received 26 September 1988
}

\begin{abstract}
Gallium phosphide is a typical III-V compound semiconductor and is also an important electronic material. The synthesis and single crystal growth of this compound by melt methods is rendered very difficult because of the large phosphorus vapour pressure. A high pressure vessel with internal heating and a quartz reactor was first developed for the direct synthesis of gallium phosphide. The crystal growth was carried out in a second high pressure chamber rated for 100 bars gas pressure and equipped with the paraphernalia for crysial growth. Single crystals of gallium phosphide were grown from the polycrystalline starting material by the vertical Bridgman method and the vapour pressure problem was overcome by encapsulating the melt in a column of molten boric oxide. Both boron nitride and silica were employed as crucibles, and with the former, single crystal rods of $8-10 \mathrm{~mm}$ diameter and $10.15 \mathrm{~mm}$ length were obtained.
\end{abstract}

Keywords. Gallium phosphide; direct synthesis; liquid encapsulated vertical Bridgman technique; crystal growth of electronic materials.

\section{Introduction}

Gallium phosphide is a member of the important class of III-V compound semiconductors whose applications as electronic materials is well known (De Kock 1980; Hilsum and Rose-Innes 1961; Kirkpatrick et al 1985; Wearden 1974). As substrates for devices, the material is required in the form of a disc with crystalline perfection, as well as precisely controlled stoichiometry, doping levels and homogeneity. Synthesis and crystal growth of III-V compound semiconductors continue to intrigue the materials scientist. One of the problems posed by these materials, especially when the V component is highly volatile as in the case of GaP, is the high vapour pressure generated at the melting point. Thus when preparation of the single crystals from the melt is attempted, vapour pressure has to be contained in order to prevent the loss of the volatile component and the consequent deviation from stoichiometry. The first single crystal growth of gallium phosphide was reported by Bass and Oliver (1968). A liquid encapsulation technique was offered as a solution to contain phosphorus vapour, and boric oxide was identified as the most suitable encapsulant (Mullin et al 1965). For GaAs, the compound can be prepared from the elements in-situ in the crystal growing equipment. But, for $\mathrm{GaP}$, we found it more convenient to synthesize the compound separately and then grow the crystals. The methods reported for GaP crystal growth are: liquidencapsulated Czochralski (LEC) (Nygren et al 1971; De Kock et al 1977; Roksnoer et al 1977) and vertical gradient freezing (VGP) (Blum and Chikota 1973; Woodbury 1976; Gault et al 1986). As no systematic study on the LEVB has been reported in the literature, we found it interesting to apply this technique to GaP crystal growth. In this paper, the synthesis of GaP directly from the elements is first 
described. The preparation of $\mathrm{GaP}$ single crystals by the liquid encapsulated vertical Bridgman method is then reported.

\section{Experimental details}

\subsection{Synthesis of GaP}

The direct synthesis of GaP from gallium and phosphorus proceeds according to the reaction:

$$
\mathrm{Ga}_{\text {liquid }}+\mathrm{P}_{\text {vapour }} \rightarrow \mathrm{GaP}_{\text {solid. }}
$$

Phosphorus starts reacting with gallium (m.p. of $\mathrm{Ga}, 29 \cdot 5^{\circ} \mathrm{C}$ ) at $700^{\circ} \mathrm{C}$, forming a crust of $\mathrm{GaP}$ on the surface of molten gallium. The crust inhibits further reaction between the two elements, but complete reaction occurs once the melt temperature is raised above the melting point of $\mathrm{GaP}\left(1467^{\circ} \mathrm{C}\right)$. For congruent melting, it is essential to have a phosphorus vapour pressure of at least 36 bars. An indigenously fabricated reactor, basicaily comprising a pressure vessel, an internal resistance heater for controlled heating to generate the requisite phosphorus vapour pressure, an internal RF work-coil with the feed through for heating reactants to $1500^{\circ} \mathrm{C}$, a transparent window to monitor temperature pyrometrically and a host of high pressure fittings for electrical and gas connections was used (Singh 1987). Figure 1 schematically shows the apparatus.

Gallium metal was contained in a graphite crucible, which was then placed inside a quartz ampoule containing red phosphorus. The ampoule was sealed in vacuum. It was placed inside the pressure vessel and the resistance heater was employed to gradually heat the phosphorus reservoir to $550^{\circ} \mathrm{C}$. The phosphorus vapour pressure generated inside the quartz ampoule was balanced by simultaneously raising the inert gas pressure inside the pressure vessel, so that the quartz ampoule did not experience any pressure difference. An RF coil was used to heat the gallium metal to $1500^{\circ} \mathrm{C}$. Once the reaction was complete the compound was homogenized and

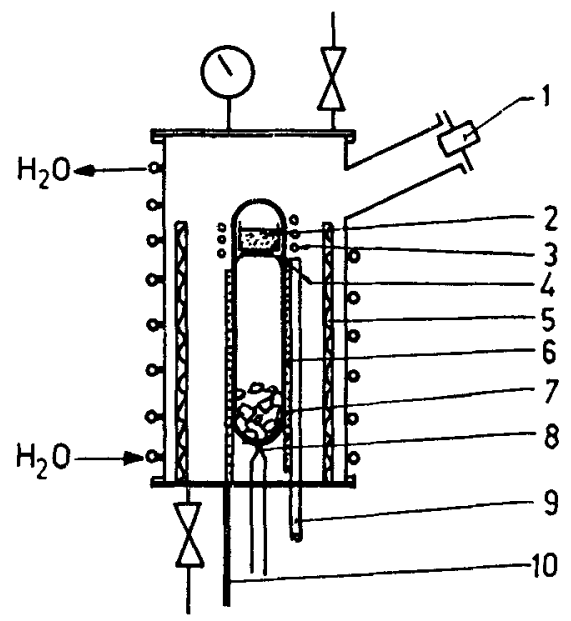

Figure 1. Apparatus for synthesis of gallium phosphide. (1) Window for pyrometer, (2) gallium, (3) RF coil to heat gallium, (4) graphite crucible, (5) shield, (6) quartz capsule,

(7) red phosphorus, (8) thermocoupie, (9) RF feed-through, (10) electrical feed-through. 
characterized by the usual powder X-ray diffraction technique to ensure that it was entirely in the single phase.

\subsection{Preparation of boric oxide encapsulant}

Before taking up crystal growth, the encapsulant had to be prepared. Boric oxide was used as the encapsulant and as pointed out earlier it prevents the loss of volatile components during the growth of compound semiconductors. The material readily absorbs moisture, and the moisture content has to be kept below a certain level. The preparation and handling of this material is therefore an involved process. We have developed in our laboratory a novel method to produce boric oxide rods starting from boric acid, the details of which are published elsewhere (Govinda Rajan et al 1988). Here, it is enough to mention that boric oxide was prepared from boric acid in a crucible and rods were pulled out from the melt using standard crystal pulling methods. The transparent moisture-free rods of boric oxide were stored in an oven at aroun $200^{\circ} \mathrm{C}$ and transferred to crucibles at the time of growth.

\subsection{Single crystal growth of GaP}

The literature on single crystal growth of GaP is rather sparse. For preparing single crystal rods of these materials so that wafers can be sliced from them, the melt methods are the most suitable. The various processes under the class of melt methods are (Brice 1986): Czochralski, Bridgman, Kyropoulos, vertical gradient freeze and floating zone. As mentioned earlier, of these only the LEC and VGF have been developed. The vertical Bridgman has not been tried and Horowitz and Horowitz (1986) have discussed the merits and demerits of the method.

Figure 2 shows the cross-section of the crystal growth equipment and the configuration of the Bridgman furnace. In the Bridgman furnace various heating zones are identified. The height of the furnace limits the size of the crucible to about $9 \mathrm{~cm}$. Both silica and boron nitride crucibles were tried. The crucibles had the standard shape required for vertical Bridgman work. The synthesised polycrystalline GaP ingot was placed in the Bridgman type silica crucible. Freshly prepared boron oxide was filled at the top. The crucible was then placed in the crystal growth station and the vessel was filled with inert gas to a pressure of 50 bars. The crucible was slowly raised into the hot zone in such a manner that the boron oxide melted first and covered the GaP before the latter started getting heated. After the entire crucible reached the set temperature of $1520^{\circ} \mathrm{C}$, it was held at this position for a few hours. The growth process was started by lowering the crucible at the rate of $0.2 \mathrm{~mm} / \mathrm{min}$. Care was taken to hold the temperature stable when the tip of the Bridgman crucible was passing through the temperature gradient so that single crystal nucleation was aided. The lowering of the crucible took many hours and once the top portion of the GaP had solidified, the furnace temperature was slowly reduced to avoid any thermal shock to the crystal. The vessel was then depressurised and the crucible removed from the furnace. The GaP crystal was extracted from the crucible by placing it in hot water and dissolving the boric oxide. With boron nitride crucibles no simple method was found to remove the GaP single crystal ingot. 


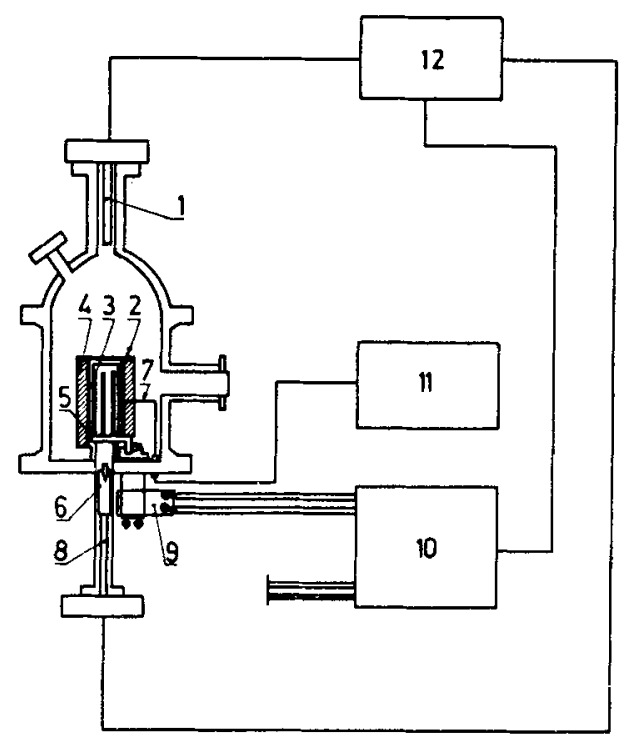

Figure 2. Layout of the high pressure single crystal growth station: (1) crystal shaft, (2), (4), (5) graphite radiation shields, (3) graphite resistance heater, (6) crucible charged with $\mathrm{GaP}$ and $\mathrm{B}_{2} \mathrm{O}_{3}$. (7) thermocouple, (8) crucible shaft with translational and rotational movements, (9) electrical feed throughs, (10) low voltage high current power supply for heater. (1 l) digital temperature indicator, (12) control panel. Not shown in the figure are the gas lines in the bell-jar shaped pressure vessel.

\section{Results}

The successful growth of a crystal especially by the LEVB technique obviously depends on the ability to remove the crystal from the crucible. This is necessary to avoid any damage or strain to the grown crystal. It was found that with silica, due to the differential contraction between boric oxide and silica and also possibly due to any devitrification suffered by silica during cooling, the crucible was invariably cracked. This resulted in the fragmentation of GaP single crystal ingots. However, each of these pieces were found to be perfect single crystals and their sizes ranged from 1-8 $\mathrm{mm}$ as shown in figure 3 . It was noted that the crystals were translucent and deep orange coloured.

With boron nitride the crucible-cracking problem did not occur, instead the crucible had to be cut for removing the crystal. A picture of a typical wafer cut from the ingot produced using a boron nitride crucible is shown in figure 4 . The state of the art of $\mathrm{GaP}$ crystal growth uses pyrolytic boron nitride crucibles which can be utilised for three to four runs.

Crystals having a good cleavage plane were selected and mounted on the goniometer head which in turn was placed in a flat plate Laue camera. The cleavage plane was optically adjusted perpendicular to the X-ray beam and a forward-reflection Laue picture taken. A typical picture is shown in figure 5. From this it can be seen that the quality of the crystal is very good. Further characterization is in progress. 


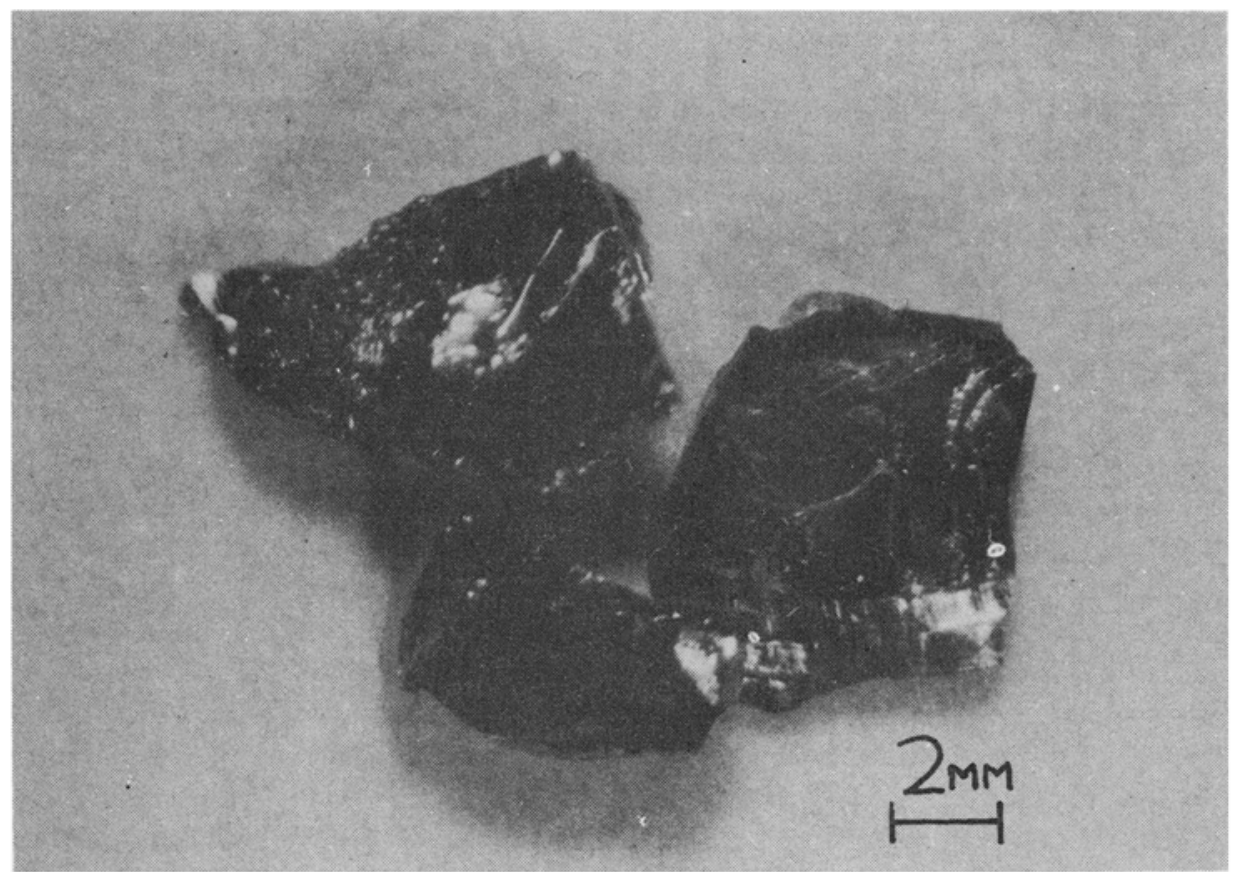

Figure 3. Photograph of single crystals of GaP grown in silica crucibles.

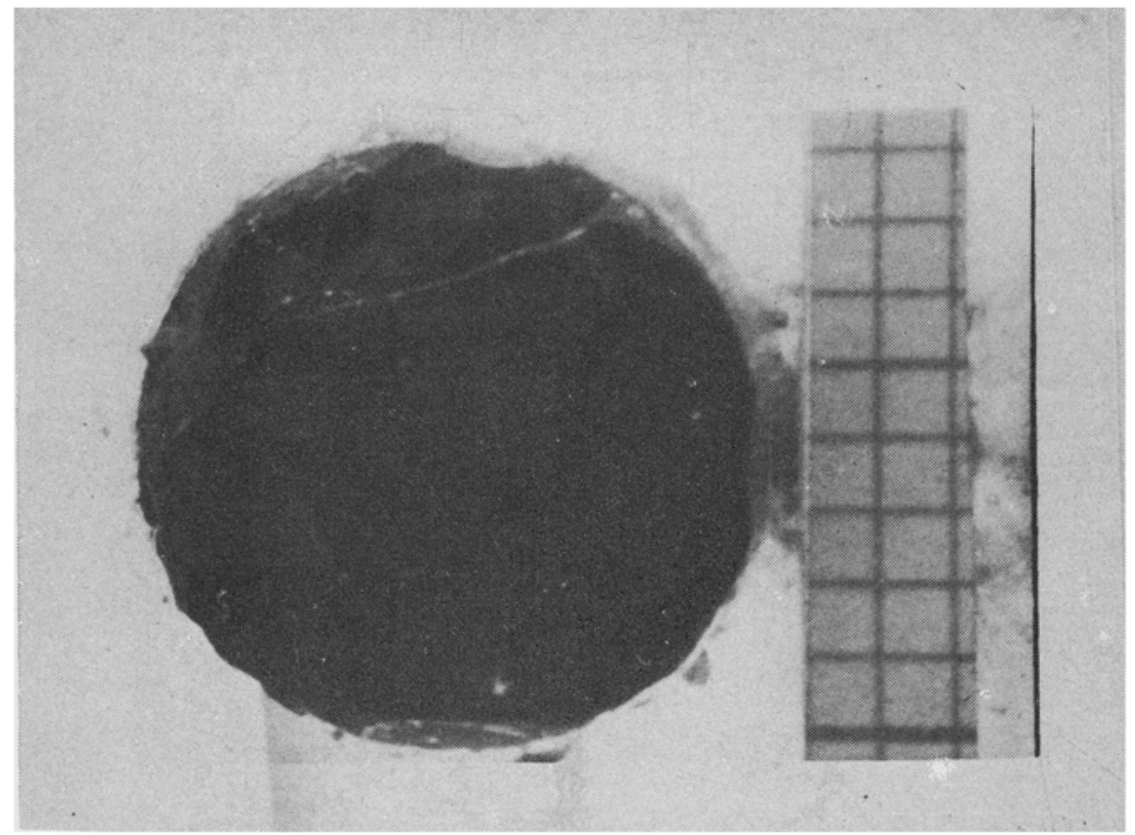

Figure 4. Photograph of a typical wafer cut from the GaP single crystal ingot produced using $B N$ crucible. (A grid indicates $1 \times 1 \mathrm{~mm}$ ). 


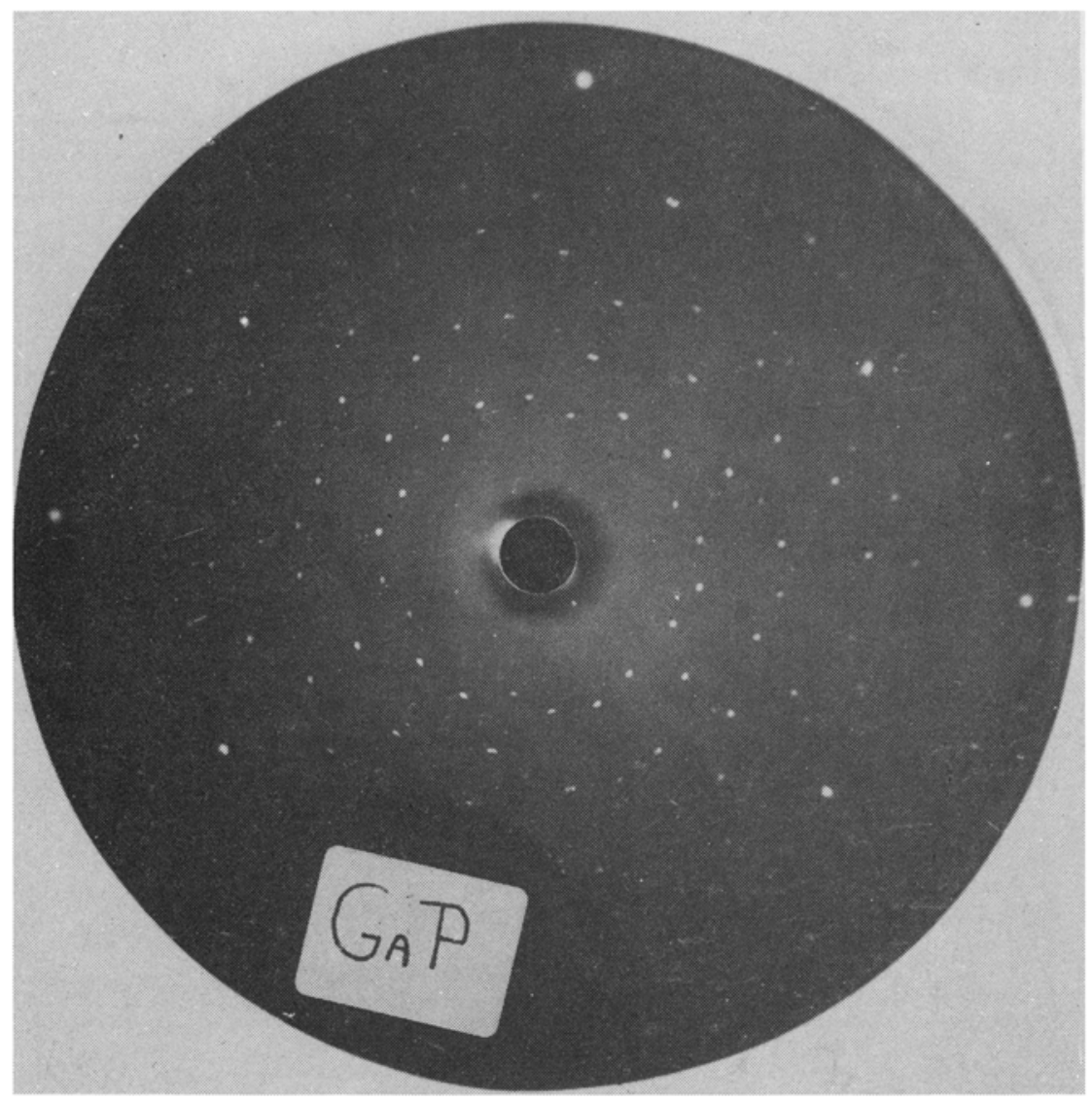

Figure 5. Forward-reflection Laue picture of GaP single crystals.

\section{Acknowledgement}

The authors at IGCAR thank Dr P Rodriguez for his encouragement and support throughout the course of this work and Shri M Sekar for skillful assistance.

\section{References}

Bass S J and Oliver P E 1968 Crystal Growth 3286

Blum S E and Chikota R J 1973 J. Electrochem. Soc. 120588

Brice J C 1986 Crystal yrowth processes (London: Blackie and Son)

De Kock A J R 1980 Handbook on semiconductors (eds) T S Moss and S P Keller (Amsterdam: North-Holland) vol. 3, p. 247

De Kock A J R, Van De Wijgert W M, Hengst J H T, Roksnoer P J and Huybregts J M P L 1977 J. Cryst. Growth 4613

Gault W A, Monberg E M and Clemens J E 1986 J. Cryst. Growth 74491

Govinda Rajan K, Chandra Shekar N V, Sckar M and Selvakumar D C C 1988 Bull. Mater. Sci. 10181

Hilsum C and Rose-Innes A C 1961 Semiconducting $I I I V$ compounds: Series on Semiconductors Volume 1 (ed.) H K Henisch (London: Pergamon)

Horowitz A and Horowitz Y S 1987 Mater. Res. Bull. 211123 (and references cited therein) 
Kirkpatrick C G, Chen R T. Homes D E and Elliott K R 1985 Gallium Arsenide (eds) M J Howes and D V Morgan (New York: John Wiley and Sons) Chap. 2, p. 39

Mullin J B, Straughan B W and Brickell W S 1965 J. Phys. Chem. Solids 26782

Nygren S F, Ringel C M and Verleur H W 1971 J. Electrochem. Soc: SOLID STATE SCIENCE 118306

Roksnoer P J, Huybregts J M P L, Van De Wijgert W M and De Kock A J R 1977 J. Cryst. Growth 406

Singh A J 1987 Proc. Indo-German Seminar on Trends and Techniques in Modern Materials Research, Kalpakkam (in press)

Wearden T 1974 Electronics and Power (March) 211

Woodbury H H 1976 J. Cryst. Growth 3549 